\title{
An ontology to represent energy-related occupant behavior in buildings Part I: Introduction to the DNAs Framework
}

\author{
Tianzhen Hong ${ }^{1, *}$, Simona D'Oca ${ }^{1,2}$, William J.N. Turner ${ }^{1,3}$, Sarah C. Taylor-Lange ${ }^{1}$ \\ ${ }^{1}$ Lawrence Berkeley National Laboratory, 1 Cyclotron Road, Berkeley, California, CA 94720, USA \\ ${ }^{2}$ Polytechnic of Turin, Energy Department, TEBE Group, Technology Energy Building Environment, Italy \\ ${ }^{3}$ University College Dublin, School of Mechanical and Materials Engineering, Belfield Campus, Dublin, \\ Ireland
}

*Corresponding Author. Email: thong@lbl.gov, Phone: (510) 486-7082, Fax: (510) 486-4089

\begin{abstract}
Reducing energy consumption in the buildings sector requires significant changes, but technology alone may fail to guarantee efficient energy performance. Human behavior plays a pivotal role in building design, operation, management and retrofit, and is a crucial positive factor for improving the indoor environment, while reducing the energy use at low cost. Over the last 40 years, a substantial body of literature has explored the impacts of human behavior on building technologies and operations. Often, need-action-event cognitive theoretical frameworks were used to represent the human-machine interactions. In Part I of this paper, a review of more than 130 published behavioral studies and frameworks, was conducted. A large variety of data-driven behavioral models were developed based on field monitoring of the human-building-system interaction. Studies emerged scattered around the world, lacking in standardization and consistency, thus leading to difficulties when comparing one with another. To bridge these gaps, an ontology to represent energy-related occupant behavior in buildings is presented. Accordingly, the technical DNAs framework is developed based on four key components: i) the Drivers of behavior, ii) the Needs of the occupants, iii) the Actions carried out by the occupants, and iv) the building systems acted upon by the occupants. This DNAs framework is envisioned to support the international research community to standardize a systematic representation of energy-related occupant
\end{abstract}


behavior in buildings. Part II of this paper further develops the DNAs framework as an XML (eXtensible Markup Language) schema, obXML, for exchange of occupant information modeling and integration with building simulation tools.

Keywords: Occupant behavior, building energy, ontology, human-building-system interaction, simulation, modeling

\section{Introduction}

To secure sustainable energy development in the buildings sector, occupant behavior needs to be directed towards a more efficient use of energy. Due to the stochastic nature of occupant behavior, the mutual influences between humans, buildings, and the environment cannot be described in a simplistic way. Rather, it requires appropriate methodologies and techniques to be able to describe and reproduce the intricate network responsible for real energy performance during the whole-building life cycle (design, operations and maintenance, retrofit). In 2013, the buildings sector was responsible for $41 \%$ of the total energy consumption in Europe [1] (27\% for residential buildings and 14\% for commercial buildings) and in the United States [2] (22\% for residential buildings and 19\% for commercial buildings). In 2010, China's buildings sector surpassed the United States as the largest consumer of energy in the world, with carbon dioxide emissions following an increasing trend [2]. The energy crisis, diminishing natural resources and global warming are driving developed countries to conserve energy in the buildings sector. Organizations are making strong efforts to accelerate the uptake of energy-efficiency technologies and practices in buildings, by setting aggressive goals at different governmental levels. However, technology alone does not guarantee low energy use in buildings. Achieving energy conservation is a dual challenge: partly technical and partly human. As stated by Turner and Frankel [3], "as technical performance standards ratchet tighter, behavioral factors gain relative importance". Consequently, so-called energyefficient green buildings exhibit large fluctuations in energy consumption due to how occupants interact 
with building systems. Figure 1 shows the distribution of delivered energy use intensities (EUIs) for U.S. commercial buildings (Baltimore, MD) occupied by financial institutions. Even omitting the extreme cases, the EUIs can vary by up to a factor of five, from around 40 to $200 \mathrm{kBtu} / \mathrm{ft}^{2} /$ year [4].

Figure 1: Distribution of delivered energy use intensities for commercial buildings in Baltimore, USA [4].

With reference to residential buildings, Andersen et al. [5] analyzed the energy consumption of a block of 35 apartments located near Copenhagen, Denmark. The apartments had almost identical characteristics in terms of orientation, building system and building envelope composition. Results showed that differences in household behavior might lead to differences in energy consumption by a factor of three, omitting the extreme cases (Figure 2). Similarly, a study conducted on measured residential summer air-conditioning electricity consumption in China [6] showed that EUIs varied dramatically, up to a factor of 10, across apartments of similar sizes within a single building (Figure 3).

Figure 2: Energy consumption of 35 apartments within the same block in Copenhagen, EU [5].

Figure 3: Residential building summer air-conditioning electricity consumption, Beijing, China [6].

Energy efficiency in buildings is not just about new technologies, it's about optimal decisions and an overall improvement of human behavior. The paper refers alternately to "human" behavior with respect to the more general concept of the stochastic nature of a human being and to "occupant" behavior when specifically indicating the actions undertaken by the building users. Occupant behavioral changes in the use of energy and water will help ensure a sustainable future for the buildings sector. This study focuses on energy-related building occupant behavior, taking into account actions and activities people perform in buildings to provide themselves with good indoor environmental quality (IEQ) (thermal comfort, visual comfort, acoustic comfort, indoor air quality, etc.). To define what is meant by energy-related occupant behavior, the International Energy Agency (IEA) Energy in Buildings 
and Communities Programme (EBC) Annex 53, “Total Energy Use in Buildings: Analysis and Evaluation Methods" [7], dedicated a section to occupant behavior modeling [8]. The term 'behavior' refers to “observable actions or reactions of a person in response to external or internal stimuli, or respectively actions or reactions of a person to adapt to ambient environmental conditions such as temperature, indoor air quality or sunlight". Annex 53 introduced quantitative descriptions of occupant behavior in the field of building energy performance, and reviewed probabilistic models for predicting occupant behavior in residential and office buildings. Hundreds of ongoing studies among the international scientific community focus on understanding how energy-related behaviors impact building energy performance. New methodologies (modeling approaches) and techniques (monitoring hardware and software platforms) for analyzing real building total energy use and for investigating the factors which influence occupant behavior in buildings, have emerge. In all of these studies, macroeconomic, cultural and climatic factors accounted for some of the locational variation, but not the variation across users. Different researchers and groups have developed models intended to predict the energy impact of building occupants. Studies scattered across the world (Europe, North America, Japan, and China), used different methodologies, and introduced different variables, instances, metrics, climates and contextual and cultural differences. Moreover, no standardized way of reporting or comparing results from different studies has emerged. This lack of structure in the field means that behavior models are difficult to compare and can be difficult to incorporate into building simulation tools. Currently, building simulation tools are used to predict the energy use of buildings during the design phase. It is this predicted energy use to which the real, operating energy use of the building is compared. While the building physics models and algorithms used by the simulation tools are now fairly mature, there is a distinct shortcoming in quantifying the energy use attributable to the building occupants.

The analysis methods, developed models and results of Annex 53 were taken as the starting point for the newly dedicated IEA EBC Annex 66, "Definition and Simulation of Occupant Behavior in Buildings" [9]. Through Annex 66, a survey was circulated to experts in the field on the use of occupant behavior 
models in simulation tools. The results indicated that among researchers, energy modelers and software developers, no common consensus has been reached on the standardization of modeling approaches, simulation tool usability and documentation or interoperability issues. Significantly, none of the surveyed experts appeared satisfied by the quality of existing models of energy-related behavior in buildings.

To address these issues, a DNAs 'Drivers - Needs - Actions - Systems' framework providing an ontology to standardize the representation of energy-related occupant behavior in buildings, is described in this study. The study is composed of two parts (Part I and Part II).

In Part I of this paper, Section 1 introduces the issues related to energy-related occupant behavior in buildings and highlights the needs for the proposed ontology. Section 2 contextualizes the DNAs framework. Section 3 provides a review of more than 130 published investigation studies on the monitoring, modeling and simulation of energy related behavior in buildings to support the structure of the DNAs framework. Finally in Section 4, the technical details of the DNAs framework are illustrated, based on four key components: i) the drivers of behavior, ii) the needs of the occupants, iii) the actions carried out by the occupants, and iv) the building systems acted upon by the occupants. Part II of this paper describes the DNAs ontology in the form of an XML (eXtensible Markup Language) schema known as obXML (occupant behavior XML), and discusses its potential applications.

\section{Review of human behavioral frameworks}

Theorized in the literature over the last 40 years are several frameworks describing human behavior using a need-action-event cognitive process. Table 1 lists nine cognitive-behavioral frameworks that consider users as reactive agents instead of passive receptors within a contextual environment. These models try to capture the stochastic nature of the human cognition process by describing the connection between the human 'inside world' inputs (drivers and needs) and the environmental 'outside world' outputs (actions and events). The nine cognitive-behavioral frameworks are described as follows:

Table 1. Theoretical frameworks of human behavior 
- Perceptual Control Theory (PCT) is one of the earliest theories of human cognitive behavior conceptualized by Powers [10]. PCT is based on the principle that "behavior is the control of perception". The 'controlling' behavior fits in between the reaction to external events and circumstances such as stimuli, reinforcements (drivers), and the generation of actions by cognitive plans or needs.

- Human Operator Simulator (HOS) was proposed by Wherry [11] to describe human behavior as interactions among agents. The agents represented different user types in a specific environment, able to perform different tasks and activities for which no executive or pre-defined schedules or controls existed.

- Cognitive Complex Theory (CCT) was proposed by Card et al. [12] as a framework of the human cognition based on the concept of Goal - Operator - Method - Selection (GOMS) topology. Accordingly, users attain their goals through rational actions. Given the structure of the task, the inputs coming from the contextual environment are systematically organized based on users' experiences, abilities and available devices and hence selected to perform actions.

- The Executive Process Interactive Control (EPIC) framework was proposed by Kieras and Meyer [13] and was suited for modelling human multi-task performances, especially in the field of humancomputer interactions.

- The State, Operator and Result (SOAR) framework was proposed by Lehman et al. [14]. Human behavior was modelled as movement throughout the space environment, in a specific time and as a function of the goal which motivated the driver to solve a task.

- The Adaptive Control of Thought (ACT) framework was proposed by Anderson and Liebere [15]. ACT is a cognition framework that can be used to implement predictive models of human behavior. Specifically, ACT focused on how humans organize their knowledge in order to behave intelligently.

- The Cognition as a Network of Tasks (COGNET) framework was proposed by Zachary et al. [16] as a theoretical framework of tools and techniques for building real-time models of human interactions 
within multi-tasking environments. In the COGNET framework, the 'outside world' (visual, acoustical and thermal environments) is conceptualized as human sensations and perceptions. The model developed a human-working memory which translated these 'inside world' inputs into cognitions (drivers, needs, etc...) leading humans into physical actions.

- The Architecture for Procedure Execution (APEX) framework was postulated by Freed [17] to simulate the human performance in complex, dynamic environments. APEX is a model used to predict human actions based on limited information resources, also taking into account human error causing system performance to deviate under certain circumstances.

- More recently, the Business Redesign Agent-Based Holistic Modelling System (BRAHMS) was proposed and tested by Sierhuis et al. [18] as a multi-agent modelling environment for simulating work practices in working spaces, such as users' interaction, activities, use of tools as well as presence and movement over time.

Most of the mentioned models captured the stochastic and reactive nature of human behavior in a complex environment, simulating users as agents acting in a specific space as a function of time. However, none of the models focused on energy-related behavior in the building indoor environment, framing the cognitive processes of the 'inside world' that lead building occupants to perform actions in the 'outside world', such as interacting with control systems in the building spaces, when driven by needs from the 'inside world'.

\section{Review of Occupant Behavior Investigation Methodologies}

Over the last few decades, a number of studies have focused on overcoming the 'credibility gap' [19] the loss of credibility when designed building energy performance and actual building energy consumption differ substantially due to variations in operation. Researchers have devised various approaches to assess the impact of occupant behavior on building energy performance. A stochastic 
approach to modelling occupant behavior has recently gained popularity, in contrast to the static description of occupant behavior based on assumptions made using fixed profiles. This new approach accounts for the fact that occupants do not always make logical choices and act stochastically rather than deterministically [20]. The human-building interaction has been typically studied according to a threestep methodology: monitor, model, simulate, with the eventual outcome including validation (Figure 4).

Figure 4: Graphical representation of the methodological approach on occupant behavior modeling

Existing monitoring studies of drivers, needs, actions and systems, behavioral models, and simulation studies, have captured the principal aspects of energy-related human behavior within a building (See Appendices for detail). Monitoring studies which assessed the correlations between building components and control system states, have mostly focused on windows, shades and blinds, lighting systems, thermostat set points, space occupancy, and electrical equipment. From the correlations identified in this review, the behavioral ontology was developed and refined.

\subsection{Monitoring studies}

Researchers have monitored building systems (i.e. natural ventilation, heating, shading or lighting systems) in order to identify the correlation between observed system states (i.e. window open/closed), indoor and outdoor conditions/variables (i.e. indoor and outdoor air temperature, relative humidity), subjective occupant behaviors and energy performance. Two main methodological approaches, one more objective (field monitoring) and one more subjective (self-reporting and questionnaires) are used widely by the scientific community to gain a better understanding of energy-related occupant behavior in buildings (See Appendix A for details) [21-90]. 


\subsubsection{Field monitoring}

In almost all of the published experimental studies, observations of occupant behavior are coupled with 'primary indicators' such as indoor and outdoor environmental conditions. This includes data from a large array of field sensors (thermometers, anemometers, globe thermostats, $\mathrm{CO}_{2}$ sensors, lux meters, photometers, etc.) as well as from weather stations (outdoor temperature and relative humidity, wind speed, rainfall, solar radiation and solar hours, etc.). Data collection techniques often include direct monitoring of the building control systems, using magnetic switches for windows [22-26], electromechanical sensors for shading systems, blinds and electric lighting [27-32], recording TRV (thermostatic radiator valve) switches [26, 33-35], AC thermostat set points [36,37], presence detectors such as motion sensors [38-40], intelligent control of building systems and real-time building visualization [41], security systems [42], PIR passive infrared sensors [43], ultrasonic detectors for light switching [44], and smart/wireless electric outlet meters [45-52]. Occupant behavior can also be indirectly monitored by sensing 'secondary' environmental variables, parameters or actions and extrapolating information. Relevant secondary indicators include the $\mathrm{CO}_{2}$ concentration level [26, 53-54], other tracer gas techniques [55-58], or metering the building energy flows (thermal, hydronic, power, etc.) [59]. Surrogate information on energy related behaviors can be deduced by using already available data such as occupancy derived from light switch sensors [41, 58-60], computer switches [61, 62], information technology (IT) infrastructure [63] and from equipment load profiles [64]. Other widespread techniques to monitor control system state or occupancy movement and presence include imaging analysis such as time lapse photography taken from the exterior building façade $[23,28,29,32,65-73]$ as well as camera-based $[74,75]$ and internal personal visual survey, such as personal building walkthroughs $[28,31,41,73,76]$.

\subsubsection{Questionnaires and self-reporting}

Another data collection approach is to ask occupants to provide information through self-reporting [26] or by using different interview techniques such as questionnaires $[23,24,29-31,37,50,52,55,65,73,77$ - 
87], web-based questionnaires [88], computer-assisted telephone interviews [33, 89] or mail surveys [90]. Questionnaire surveys are often used to identify the most important factors affecting the occupant's interaction with building control systems including: window opening behavior $[23,24,26,55,73,76-78$, 88], the use of heating [26, 33, 83, 85, 89] and cooling [37, 84, 87], solar shading and blinds [20, 26, 29, 65], electrical lighting [26, 31, 81] and equipment [52, 86]. The surveys are typically carried out by sending out invitations to a consistent amount of building occupants which are representative of the building population. Subjects are asked about preferences in control system settings and repetitive actions. Often self-reporting techniques are used to record the human-building interaction when direct monitoring is not allowed. Data on occupant behaviors and preferences are typically coupled with information on dwelling characteristics, meteorological and census data (when available).

\subsection{Modelling studies}

Based on monitoring and questionnaire data, researchers have investigated which predictor variables drive occupant decisions to interact with the building systems. Behavioral models are then developed to predict the probability of an occupant interacting with a building system. Implicit models are used to understand the driving forces behind the behavior itself or to predict the state of a building system or the occurrence of an occupant's action, based on the predictor variable. Explicit models are used to provide a personalized description (or future prediction) of the state of a building system or the actions of an agent, (i.e. the occupant in a building), based on the monitored real behavior (movement and control action) of the agent itself (See Appendix B) [91-134]. In both cases, statistical and data-mining methods are used to obtain information on repetitive patterns of occupant behaviors and human-building interactions, and to provide insights into user profiles related to occupant behavior [42, 131-136]. 


\subsubsection{Implicit models}

Implicit models of energy-related human behavior include linear regression models [36, 37, 55, 76, 91], logistic regression models with a single variable $[22,23,25,29,37,47,48,68,73,92-100]$ or multivariate variables $[27,35,36,53,68,92,101-109]$. Other types of statistical models have been used to simulate the stochastic nature of human interaction in buildings, such as simple probability equations [42, 71, 72, 110-112], sub-hourly occupancy-based control models (SHOCC) [113] and Bayesian estimations [114].

\subsubsection{Explicit models}

Explicit models of human behavior are commonly based on occupancy presence and movement data and are used to predict the probability distribution of an event (e.g. occupant being present in a space) or behavior (e.g. occupant moving within a space) to occur. Such action- and agent-based models are centered on the use of random numbers to generate stochastic variables. Typical Monte Carlo methods are Markov Chain models [32, 49, 50, 73, 115-120], as well as discrete [21, 80] and semi-hidden [38, 121123] Markov Chain models. State transition analysis is also used to develop real-time agent- and actionbased models [124-130].

\subsubsection{Data mining to support modeling studies}

In the last 10 years several systematic data-mining methodologies (Cluster Analysis, Association Rules Mining, Decision Tree, and Rule Induction) [42, 131-136] have been tested to identify and improve occupant behavior modeling in buildings.

Due to the stochastic nature of human behavior evolving randomly with time, in many applications it is difficult to extrapolate useful building occupant information from monitored buildings by means of statistical analysis. Due to the data scattering at this level, statistical analysis techniques may fail in obtaining reliable mathematical models by over fitting or 
under fitting the data. Instead, patterns of data discovered through data mining techniques may highlight commonsense knowledge, applicable to fit both direct and indirect models. In this context, data mining techniques have been shown to automatically extrapolate valid, novel, potential useful and understandable building occupant patterns from big data streams $[134,150]$. Data mining techniques are not intended to substitute or contrast the direct stochastic models or indirect agent-based models already developed for the integration of occupant behaviors into building energy simulations. More likely, the knowledge discovered through data mining techniques aims to overcome the shortcomings of more traditional techniques, specifically when dealing with big data streams, by providing reliable models of energy related behaviors with fast legibility and high replication potential.

\subsection{Simulations}

Mathematical models of human behavior translated into computer simulation draw the connection between the theoretical world and the observed world. Researchers have incorporated behavioral models into building energy simulation tools with the aim of predicting and leveraging the impacts of occupant behavior on 1) building energy performance, 2) comfort levels and 3) indoor air quality (IAQ). The most widespread building simulation tools are EnergyPlus [137], IDA Ice [138], ESP-r [139], TRNSYS [140], DeST [141], and DOE-2 [142]. In some cases, ad-hoc software tools, simulation engines, interfaces or wizards have been used to simulate specific aspects of human behavior (i.e. DAYSIM [143] and Lightswitch Wizard in Visual Studio [144]). Simulation engines allow researchers to assess the implications of different stochastic occupant behaviors within the context of building components and characteristics (Table 2) as well as geographical contextual factors. 
Table 2. Typical building components and characteristics included in published simulation models of occupant behavior

Different models suitable for exploring the diversity of occupant behavior over several timescales using computer simulation are proposed in the literature (for which excellent comprehensive reviews are provided by the Annex 53 Final Report [7] and Gunay et al. [20]). For each of the principal buildingsystem interactions under investigation, Table 3 illustrates the most common metrics and simulation outputs, according to published simulation studies.

Table 3. Typical metrics and simulation outputs used in published simulation models of occupant behavior

\section{The DNAs Occupant Behavior Framework}

An initial concept of the DNAs framework was proposed by Turner \& Hong [145], as a brief introduction to the DNAs 'Drivers - Needs - Actions - Systems' ontology developed in this study (Figure 5). The impact of the behavior of the occupant (or groups of occupants) on building energy use, can be described using four main components, namely drivers, needs, actions and systems. The four components inhabit the 'outside world' (i.e. the building environment) and the 'inside word' (i.e. the cognitive processes of the human being). Drivers represent the environmental factors from the outside world that stimulate occupants in their inside world to fulfill a physical, physiological or psychological need. Needs represent the physical and non-physical requirements of the occupant's inside world that must be met in order to ensure the satisfaction of the occupant with their environment. Actions are the interactions with systems or activities that an occupant can conduct to achieve environmental comfort. Actions connect occupants' inside-world needs, with the environmental outside word. Systems refer to the equipment or mechanisms within the building outside world with which an occupant may interact to restore or maintain environmental comfort. 
Figure 5: Four key components of the DNAs occupant behavior framework: Drivers, Needs, Actions and Systems

As an example of the DNAs concept, consider the following simple scenario: An occupant is working inside a naturally-ventilated office with operable windows during the summer. The indoor room temperature increases throughout the morning until the occupant becomes thermally uncomfortable. The occupant then opens the window to allow cooler outside air into the building. As a result the room temperature decreases and the occupant becomes satisfied with the indoor thermal environment. In the above example the driver is the indoor air temperature. The need is the requirement for thermal comfort of the occupant. The action is the opening of the window by the occupant. The system is the window. The nature of each component of the DNAs ontology will be discussed in Sections 4.1 to 4.4.

\subsection{Drivers}

Drivers represent the stimulating factors that provoke energy-related occupant behavior. A driver prompts a building occupant to perform either an action or in-action with a building system, impacting the energy use of a building (Figure 6). The drivers can include environmental factors, such as indoor air temperature and solar radiation, as well as non-physical factors such the time of day or the season. Within the topology of drivers, five main categories were identified, (i) building, (ii) occupant, (iii) environment, (iv) system and (v) time. 


\section{Figure 6: Drivers behind energy-related occupant behavior}

(i) Building - The building category encompasses the physical properties of the building itself that can act as drivers [146]. This includes the building's orientation (façade exposure to solar radiation), construction material, floor layout etc. The location of the building in relation to other buildings, busy roads, fields can also affect the behavior of the occupants [16].

(ii) Occupant - The attributes of an occupant relate to the occupant's age and gender [147], as well as physical mobility [148] etc. which can dictate how an occupant behaves and their response to environmental drivers and hence, how they interact with building systems. Specifically, the 'energy attitude' of the occupant is important [149-152]. The DNAs framework provides a platform to allow a range of occupant energy attitudes from 'energy frugal' to 'energy profligate' via 'energy indifferent'. The energy attitude of the occupant will govern how the occupant interacts with energy-related building systems. The location of the occupant determines their exposure to environmental drivers. The state of the occupant describes their metabolic rate and whether they are arriving at a space, remaining in a space, or departing from a space. The metabolic rate is a widely-accepted input for thermal comfort models [153, 154] and has a profound impact on occupant behavior. Window opening, blind use and lighting use have been found to be more frequent when occupants first arrive or leave, compared with when they remain in a space $[9,26,36,101-105,113,134,150]$.

(iii) Environment - Environmental factors such as climate, weather and indoor and outdoor conditions (e.g. air temperature, humidity, solar radiation, IAQ) are all fundamental drivers behind the response of occupants to their environment [155]. In the field of behavior modeling there lacks agreement as to which environmental drivers are optimal when modeling certain actions. In the example given in Section 4, the driver behind the window-opening action was given as the indoor air temperature. However, it has been argued that the indoor air temperature is actually driven by the outdoor air temperature, and so the outdoor air temperature is the real driver behind the window-opening action. To address this conflict researchers introduced the concept of direct and indirect drivers. The direct drivers immediately impinge 
on the comfort of the occupant, whereas the indirect drivers impinge upon the direct drivers. In the example of window opening, the direct driver would be the indoor air temperature and the indirect driver would be the outdoor air temperature.

(iv) System - Studies have shown that the existing state of a building system acts as a statistically significant predictor of the probability of an occupant interacting with the system. An example of this effect would be the state of a window. For example, studies have shown that once a window has been opened or closed by an occupant in the morning, the window is more likely to remain in that state, independent of other driving forces [22, 27, 134].

(v) Time - The time of day and the day of the week are fundamental to the presence and location of occupants in a building. Some personal habits are time-driven, for example opening windows when first arriving at office or closing windows before leaving the office, or turning on lights when first arriving and turning off lights before leaving. The day of the week, such as occupancy presence in office buildings or equipment usage in homes during working and non-working days. The change in season (month of the year) also affects the interactions between occupants and building systems, resulting conditions inside a building [24,147].

\subsection{Needs}

Needs represent the requirements of the occupant that must be met in order to ensure satisfaction with their surrounding environment (Figure 7). As stated by Milliken [156], "there are certain physical needs that people must meet in order to survive. There are others that make people more comfortable. In the specific ways they strive to meet these needs, people are different". An occupant will have certain criteria or expectations of their environment which relates to their overall comfort. When this criteria is met, the occupant can be described as comfortable. If the criteria is not met, the occupant can be described as uncomfortable. When the state of physical discomfort exceeds the tolerance of the user, it causes a psychological response which prompts the user to perform activities to adjust their environment (e.g. 
opening a window) or adjust themselves to the environment (e.g. adjusting clothing level). However, comfort levels are individual and may vary largely from user to user. Moreover, they are not triggered at regular thresholds, but depend upon environmental and contextual factors which fluctuate over time. Therefore, the occupant behavior for satisfying comfort needs must be taken into account. Needs can be physical or non-physical. The two categories have been chosen for the DNAs framework so that all needs could be encompassed and easily classified, while still leaving flexibility in scope.

Figure 7: Needs of building occupants that may result in an action that changes the building energy use

Physical needs include: (i) thermal comfort or satisfaction with the thermal environment, which is a combination of indoor air temperature and humidity, surrounding surface temperatures, indoor air velocity, activity level, incident radiation and clothing level of the occupant [88, 107, 153, 154]; (ii) visual comfort such as not being subjected to glare, excessive contrast or unacceptable levels of brightness; (iii) acoustic comfort, with the level of background noise within an acceptable range; (iv) indoor environmental health, meaning good IAQ or humidity. Non-physical needs include factors such as the need for privacy or the need to maintain outside views. Both of these contribute to the overall satisfaction of the occupant, but can also impact building energy performance by influencing the manner in which an occupant may interact with building systems.

\subsection{Actions}

Actions are interactions with systems or activities that an occupant can conduct in order to satisfy their needs. The violation of one or more of an occupant's needs leads to discomfort. Therefore, this uncomfortable state for the occupant will provoke an action (Figure 8). The action may be an interaction with a system in which the occupant conjectures that their action will restore comfort. An example of an action would be to adjust the level of clothing, open a window, or turn down the thermostat temperature 
etc. Actions can also include other measures such as reporting discomfort to a building manager, moving to a different location, or leaving the building entirely.

Figure 8: Actions undertaken by building occupants when their needs are not met

There is also the possibility for inaction, when the occupant decides to do nothing but to suffer the discomfort. This could be caused by the occupant deeming the effort required to mediate the discomfort too high or the occupant is without access to suitable systems. Energy attitudes and social pressure may also cause inaction, whereby an occupant modifies their willingness to perform a discomfort-alleviating action due to the presence of other occupants who would be affected by the action.

\subsection{Systems}

Systems are the equipment, mechanisms or measures with which an occupant may interact to restore comfort, or satisfaction with their environment. Systems, or building systems, describe any piece of equipment or mechanism inside a building that an occupant can interact with and can affect the energy performance of a building (Figure 9).

Figure 9: Building systems with which an occupant may interact causing a change in building energy use

For a system to affect the occupant-related energy performance of a building, it needs to be acted upon or controlled by an occupant. Common systems that are subject to occupant control and actions include windows, window blinds/shades, lights, thermostats, space occupancy, and electrical equipment. The control method of the systems becomes important when considering the energy performance of the building. Manual systems, such as non-programmable thermostats (or programmable thermostats which simply have not been programmed) and operable windows, can be directly controlled by occupants. Automated systems, such as programmable thermostats and automatic blind systems, can be acted upon 
by occupants using an override function. The clothing worn by an occupant, or the interactions which prompt feedback energy from visualization systems, can also be considered a system in the framework.

\section{Discussion}

This section discusses the possible applications of the described ontology developed to standardize the representation of energy-related occupant behavior in the buildings sector, at the international level (Figure 10).

Figure 10: A graphical representation of the DNAs framework applications

\subsection{What types of behavior are accounted for in the DNAs framework?}

Interactions between occupants and building systems can have a dramatic impact on global building performance in terms of comfort (thermal, visual, acoustical, IAQ), energy loads (heating, cooling, ventilation, lighting, plug-loads, electricity peak loads), technology efficiency, operational costs and occupant productivity. In the DNAs framework, energy-related behavior refers both to individuals and groups of occupants and their interactions with building energy services systems, appliances and facilities to control the indoor environment, such as windows, blinds and shades, heating and cooling thermostats, lighting and electric appliances. The movement and presence of occupants in indoor spaces is also included in the framework.

\subsection{Why a framework to standardize the representation of energy-related behavior in buildings?}

While building performance drivers such as climate, building envelope, and building equipment are well recognized and studied, the representation of energy-related occupant behavior is often oversimplified partly due to the stochastic nature of human behavior. The goal of the DNAs framework is to provide an ontology of energy-related occupant behavior in buildings, to solve discrepancy issues mostly rooted in: (a) oversimplifying or ignoring human behavior in the building design and operation process, (b) a broken 
interface between human behavior and building system controls and, (c) lack of reliable technology and system controls performance. The effectiveness of the DNAs framework will be measured by its capability to bridge some of the 'credibility gaps' [10] between:

- predicted vs. real energy consumption in buildings

- $\quad$ modeled vs. actual occupant behavior in buildings

- deterministic vs. stochastic nature of human behaviors in energy modeling

- $\quad$ perceived vs. realistic performance of technologies

- assumed vs monitored occupant behavior impact factor on building performance.

\subsection{Which building types can be addressed when adopting the proposed ontology?}

Occupant behavior has been shown to have a profound impact on the energy performance of both residential and commercial buildings, even within a narrowly-defined cohort of similar building types of a particular age, size, and principal use. The DNAs framework will provide researchers, designers, energy modelers, building operators, managers and policy makers with an ontology to standardize the representation of energy-related occupant behavior in buildings, and quantify its impact. Specifically, the impact on building operation scenarios, technology and system performance, as well as design and retrofit strategies. The conceived structure of the framework is generic enough to allow the description of solutions for different climate zones and geographical locations.

\subsection{Who can use the DNAs framework, for what purposes and to what extent?}

The DNAs framework will be used to address issues held by building energy modelers, building designers, building engineers, building operators and managers, building utilities, and policy makers. Building energy modelers can use the framework to simulate occupant behavior in buildings consistently. Simulation results can be shared with other modelers in a structured and consistent way. In the long term, 
the DNAs framework will allow occupant behavior modeling to become a standard component in building information modeling (BIM). Building designers will be able to use the DNAs framework for stochastic spatial mapping of occupants. Typical occupational working profiles developed using the DNAs framework will support strategic choices made during the early design and retrofit stages of buildings. Building engineers will receive strategic knowledge on performance of their technology, equipment or systems, by simulating the impact of the energy related behavior reviewed in the DNAs framework as part of overall building energy performance. Building operators and managers will profit from the knowledge collected using the DNAs framework, which will provide actionable information that allows optimal tuning of space heating/cooling set points, comfort levels, and operational schedules of HVAC and lighting systems. Building utilities will receive strategic support from the application of the DNAs framework when adjusting their priorities to user-oriented energy-efficiency requirements and behavioral programs, and also modifying their technology and equipment production. Policy makers will apply the DNAs framework to guide behavioral program design, implementation and evaluation. Also, the DNAs framework can be envisioned as the fundamental setting-body structure of a new generation of ISO (International Organization for Standardization) standards to represent and describe energy-related occupant behavior in the buildings sector at the international level.

\subsection{When the DNAs framework can be used?}

The DNAs framework can benefit building energy performance during the whole building life cycle, including the design, operations, management and retrofit phases. During the design phase, the DNAs framework allows for more accurate prediction of actual building energy use. The occupant behavior models utilizing the DNAs framework and implemented in energy modeling programs, such as EnergyPlus, will support decision making in the early design stage. During operation and maintenance the predictive models and algorithms of occupant behavior covered by the DNAs framework will advise users through smart human-machine integrated communication (i.e. embedded in personal mobile devices and 
control technologies), as well as allow for building energy flows, control systems, appliance usage, and comfort level mapping. During a building retrofit, the DNAs framework could aid in the evaluation and impact assessment of different building technology solutions influenced by occupant behavior.

\subsection{How energy-related behavior can be represented using the DNAs framework?}

The different applications of the described ontology aim to overcome some unbridged gaps in methods, models, and simulation tools, to represent the impact of energy-related occupant behavior on wholebuilding energy performance. Monitoring methods, modeling methods and simulation engines are three specific areas which will be highly influenced by the adoption of the DNAs framework. Currently, no common agreement exists among the scientific community on which data to collect, which parameters to monitor and with which sensor and accuracy, which length time step, and what duration of monitoring period. The monitoring methods of different type of behaviors and actions can be guided by the DNAs framework, eliminating ambiguity. Moreover, the DNAs framework addresses current challenges with modeling methods. The research community is in strong need of enhanced behavioral models to meet experts' requirements. Firstly, qualitative behavioral actions are not adequately supported by a common language when translated into quantitative models and simulations. Starting from the monitoring phase, gathering data over a significant time range, covering diverse building types, organizational culture, populations and geographical areas would assure statistical relevance to the model development. Nonetheless, this is rarely achieved, due to lack of resources, tools and time. The DNAs framework provides a cohesive ontology that can advance modeling methods specific to energy-related occupant behavior in buildings. Lastly, there is no common consensus as to the most effective tool to use to develop reliable behavioral simulations. Several independent codes have been written and implemented into existing simulation tools. Nonetheless, the applicability and interoperability of these models are still affected by local disparities, coding languages and design issues. Different technical advances on the implementation of behavioral models have been realized in different simulation environments. However, 
very often such advanced controls come without appropriate graphical user interfaces, making them difficult and time-consuming to learn. The proposed DNAs framework is intended to be integrated into current building energy modeling programs like EnergyPlus and other domains (ESP-r, TRNSYS, IDA ICE, DeST, DOE-2, etc.) or Functional Mock-up Interfaces (FMI) to support both model exchange and co-simulation of dynamic models using a combination of xml-files and compiled codes, within the structure of the XML Schema.

\section{Conclusion}

The DNAs framework described in this study presents an ontology providing a common technical language for the building simulation community to observe, model, and simulate energy-related occupant behavior in buildings. The proposed framework captures the vast majority of occupant behavior which directly or indirectly impacts building energy use. The ontology comprises of four main components: the drivers behind the occupant behavior that influence the energy performance of buildings; the needs of the occupants which must be met in order for the occupants to be comfortable and satisfied with their environment; the actions which occupants can take in order to satisfy their needs; and the building systems with which occupants can interact to perform the actions which affect the building energy performance. Describing, predicting or influencing energy-related occupant behavior are challenging tasks, due to the stochastic nature of humans. Currently, the field of building occupant behavior modeling suffers from a lack of standardization in methods, models and simulations. To this extent, the DNAs framework presented in this paper, facilitates the quantification of the impact of occupant behavior on building energy efficiency. The aim is to provide more robust descriptions of the motivations driving occupants to interact with the building envelope and building systems, in order to bring about desired comfort conditions. The DNAs framework is envisioned as a common information exchange language supporting stakeholders (architects, engineers, operators, owners, occupants) and policy makers, toward the standardization of the representation of energy-related occupant behavior. The final aim of the 
framework is to allow the incorporation of more accurate behavioral models into building simulation tools to provide comparable metrics and results on: 1) the behavioral factors that impact building energy performance, 2) the potential energy savings from improved occupant behavior in buildings, and 3) the design of robust building operation scenarios, technologies, systems and retrofit strategies. Applications of the DNAs framework include building energy modeling and simulation, building design, energy benchmarking and performance rating, development of codes and standards, and policy decisions. In the long term, the DNAs framework can evolve into occupant information modeling (OIM), as a new and critical addition to building information modeling (BIM). An XML schema called obXML will further implement this framework to promote comparison and validation of occupant behavior models, while also facilitating their integration with building simulation tools. The deployment of the DNAs framework and the obXML schema into current modeling practices must then face some of the intrinsic constraints of human behavior simulation in buildings, such as the level of modeling detail for individual and group behavior, the interaction between external and internal drivers and action scenarios, as well as the implication of multiple behaviors and choices in buildings [20, 22], just to mention some.

More detailed analysis of constrains for application of the DNAs framework and insights into the obXML schema are provided in Part II of this paper.

\section{Acknowledgements}

This work was sponsored by the United States Department of Energy (Contract No. DE-AC0205CH11231) under the U.S.-China Clean Energy Research Center for Building Energy Efficiency. This

work is also part of the research activities of the International Energy Agency Energy in Buildings and Communities Program Annex 66, Definition and Simulation of Occupant Behavior in Buildings.

\section{References}

[1] BPIE Database http://www.buildingsdata.eu/ 
[2] US Energy Information Administration (EIA), Annual Energy Outlook, DOE/EIA. Regional Analysis of Building Distributed Energy Costs and CO2 Abatement: A U.S.-China Comparison 2013.

[3] Turner C, Frankel M. Energy Performance of LEED for New Construction Buildings. Technical Report, New Buildings Institute, Vancouver, WA. 2008.

[4] Lawrence Berkeley National Laboratory (LBNL), U.S. Department of Energy. Buildings Performance Database 2014 at http://bpd.lbl.gov.

[5] Fabi V, Andersen RV, Corgnati SP, Olesen BW. A methodology for modelling energy-related human behaviour: Application to window opening behaviour in residential buildings. Building Simulation Journal, 2013; DOI 10.1007/s12273-013-0119-6.

[6] Energy Information Administration (EIA), U.S. Department of Energy. International Energy Outlook 2013; Report No. EIA/DOE-0484:111.

[7] IEA Annex 53 - Total energy use in buildings, Analysis and evaluation methods. Final Report IEA 2013.

[8] IEA Annex 53 - Total energy use in buildings, Analysis and evaluation methods. Occupant Behavior and modeling. Separate Document Volume II. Final Report IEA 2013.

[9] International Energy Agency. Energy in buildings and communities program. Annex 66: definition and simulation of occupant behavior in buildings; 2013-2017 http://www.annex66.org/

[10] Powers WT. Behavior: The Control of Perception, New Canaan, CT: Benchmark; 1973.

[11] Wherry Jr RJ. The Human Operator Simulator - HOS. Monitoring Behavior and Supervisory Control, NATO Conference Series 1976; 1:283-293.

[12] Card SK., Moran TP., Newell A. The Psychology of Human-computer interaction, Lawrence Erlbaum Associates, Inc; 1983.

[13] Kieras DE., Meyer DE. An overview of the EPIC architecture for cognition and performance with application to human computer interaction. The Psychology of Human-computer interaction 1997; 12:391-438. 
[14] Lehman JF, Laird J., Rosenbloom P. A gentle introduction to SOAR, an architecture for human cognition. University of Southern California, Information Sciences Institute; 2006.

[15] Anderson JR, Lebiere C. The Atomic Components of Thought. Lawrence Erlbaum Associates, Inc; 1998.

[16] Zachary WW, Ryder JM., Hicinbothom HJ. Cognitive Task Analysis and Modeling of Decision Making in Complex Environments. Decision making under stress: Implications for training and simulation. Washington, DC: American Psychological Association; 1998.

[17] Freed MA. Simulating Human Performance in Complex, Dynamic Environments. PhD Dissertation, Northwestern University, Evanston, Illinois; 1998.

[18] Sierhuis M, Clancey WJ, van Hoof RJJ. Brahms: A multi-agent modelling environment for simulating work processes and practices. Int. J. of Simulation and Process Modelling; 2007.

[19] Bordass B, Cohen R, Standeven M, Leaman A. Assessing building performance in use. Building Research and Information, 2010; 29, 2:103-113.

[20] Gunay GB, O’Brien W, Beausoleil-Morrison I, A critical review of observation studies, modeling and simulation of adaptive occupant behaviors in offices. Building and Environment, 2013; 70:31-47.

[21] Fritsch R, Kohler A, Ferguson M, Scartezzini JL. A Stochastic Model of User Regarding Ventilation Behavior. Building and Environment, 1990; 25, 2:173-181.

[22] Haldi F, Robinson D. The impact of occupants' behaviour on building energy demand. Journal of Building Performance Simulation 2011; 4:323-338.

[23] Warren PR, Parkins LM. Window-opening behaviour in office buildings. Building Serv Eng Res Technol 1984;5-89.

[24] Frontczak M, Andersen RV, Wargocki P. Questionnaire survey on factors influencing comfort with indoor environmental quality in Danish housing. Building and Environment 2012; 50:56-64.

[25] Yun GY, Steemers K. Time-dependent occupant behaviour models of window control in summer. Building and Environment 2008; 43:1471-1482. 
[26] Andersen RV, Toftum J, Andersen KK, Olesen BW. Survey of occupant behaviour and control of indoor environment in Danish dwellings. Energy and Buildings 2009; 41:11-16.

[27] Wilke U, Haldi F, Scartezzini JL, Robinson D. A bottom-up stochastic model to predict building occupants' time-dependent activities. Building and Environment 2013; 60:254-264.

[28] Inkarojrit V, Paliaga G. Indoor climatic influences on the operation of windows in a naturally ventilated building. Plea2004 - The 21th Conference on Passive and Low Energy Architecture. Eindhoven. The Netherlands; 2004.

[29] Sutter Y, Dumortier D, Fontoynont M. The use of shading systems in VDU task offices: A pilot study. Energy and Buildings 2006; 38:780-789.

[30] Sanati L, Utzinger M. The effect of window shading design on occupant use of blinds and electric lighting. Building and Environment 2013; 64:67-76.

[31] Moore T, Carter DJ Slater AI. Long-term patterns of use of occupant controlled office lighting. Lighting Research and Technology 2003; 35:43.

[32] Yao J. Determining the energy performance of manually controlled solar shades: A stochastic model based co-simulation analysis. Applied Energy 2014; 27:64-80.

[33] Karjalainen S. Thermal comfort and use of thermostats in Finnish homes and offices. Building and Environment 2009; 44:1237-1245.

[34] Alan M, Aragon C, Peffer T, Perry D, Pritoni M. Usability of Residential Thermostats: Preliminary Investigations. Building and Environment, 2011; 46:1891-8.

[35] Guerra-Santin O, Itard L, Visscher H. The effect of occupancy and building characteristics on energy use for space and water heating in Dutch residential stock. Energy and Buildings 2009; 41:1223-1232. [36] Schweiker M, Shukuya M. Comparison of theoretical and statistical models of air-conditioning-unit usage behaviour in a residential setting under Japanese climatic conditions. Building and Environment 2009; 44:2137-2149. 
[37] Tanimoto J, Hagishima A, Sagara H. A methodology for peak energy requirement considering actual variation of occupants' behavior schedules. Building and Environment 2008; 43:610-619.

[38] Dong B, Lam LK. Building energy and comfort management through occupant behaviour pattern detection based on a large-scale environmental sensor network. Journal of Building Performance Simulation 12/2011;

[39] Dong B, Lam LK. A real-time model predictive control for building heating and cooling systems based on the occupancy behavior pattern detection and local weather forecasting. Building Simulation $2004 ; 2: 7$

[40] Duarte C, Van Den Wymelenberg K, Rieger C, Revealing occupancy patterns in an office building through the use of occupancy sensor data, Energy and Buildings 2013; 67:587-595.

[41] Reinhart CF, Wienold J. The daylighting dashboard - A simulation-based design analysis for daylit spaces. Building and Environment 02/2011

[42] Emery AF, Kippenhan CJ. A long term study of residential home heating consumption and the effect of occupant behavior on homes in the Pacific Northwest constructed according to improved thermal standards. Energy 2006; 31:677-693.

[43] Dodier R, Henze H, Tiller GP, Guo X. Building occupancy detection through sensor belief networks. Energy and Buildings 2006; 38(9):1033-1043.

[44] Guo X, Tiller DK, Henze GP, Waters CE. The performance of occupancy-based lighting control systems: A review. Lighting Research and Technology 2010; 42: 415.

[45] Zhao J, Lasternas B, Lam KP, Yun R, Loftness V. Occupant behavior and schedule modeling for building energy simulation through office appliance power consumption data mining. Energy and Buildings 07/2014;

[46] Wang D, Federspiel CC, Rubinstein F, Modeling occupancy in single person offices, Energy and Buildings 2005; 37:121-126. 
[47] Richardson I, Thomson M, Infield D, Clifford C. Domestic electricity use: A high-resolution energy demand model. Energy and Buildings 2010; 42:1878-1887.

[48] Hoes P, Hensen J, Loomans M, Devries B, Bourgeois D. User behavior in whole building simulation. Energy and Buildings, 2009; 41(3):295-302.

[49] Stokes M, Rylatt M, Lomas K, A simple model of domestic lighting demand, Energy and Buildings 2004; 36:103-116.

[50] Parys W, Saelens D, Hensa H. Coupling of dynamic building simulation with stochastic modelling of occupant behaviour in offices - a review-based integrated methodology. Journal of Building Performance Simulation 2011; 4.

[51] Widen J, Nilsson A, Wäckelgard E, Constructing load profiles for household electricity and hot water from time use data - modelling approach and validation, Energy and Buildings 2009; 41:753-768.

[52] D’Oca S, Corgnati SP, Buso T. Smart meters and energy savings in Italy: Determining the effectiveness of persuasive communication in dwellings. Energy Research \& Social Science 2014; 3:131142.

[53] Dutton S., Shao L. Window opening behavior in a naturally ventilated school. Fourth National Conference of IBPSA-USA New York City; 2010.

[54] Guillaume AA. Estimating Occupancy Using Indoor Carbon Dioxide Concentrations Only in an Office Building: a Method and Qualitative Assessment. Proceeding of Clima 2013 Prague.

[55] Bekö G, Toftum J, Clausen G. Modeling ventilation rates in bedrooms based on building characteristics and occupant behavior. Building and Environment 2011; 46:2230-2237.

[56] Iwashita G, Akasaka H. The effects of human behavior on natural ventilation rate and indoor air environment in summer- a field study in southern Japan. Energy and Buildings 1997; 25:195-205.

[57] Kvistgaard B, Collet PF. The User's Influence on Air Change, Air Change Rate and Air Tightness in Buildings. American Society for Testing and Materials 1990:67-76. 
[58] Wallace LA, Howard-Reed C, Ott WR. The Effect of Opening Windows on Air Change Rates in Two Homes. J. Air \& Waste Manage. Assoc. Technical Report. 2002; 52:174-185.

[59] Chang W., Hong T, Statistical Analysis and Modeling of Occupancy Patterns in Open-Plan Offices using Measured Lighting-Switch Data. Building Simulation 2013; 6:23-32.

[60] Boyce PR. Observations of the manual switching of lighting. Lighting Research and Technology 1980:12-195.

[61] Branco G, Lachal B, Gallinelli P, Weber W. Predicted versus observed heat consumption of a low energy multifamily complex in Switzerland based on long-term experimental data. Energy and Buildings 2004; 36:543-555.

[62] Tarzia SP, Dinda PA, Dick RP, Memik G. Display power management policies in practice. Proceeding of the 7th international conference on Autonomic computing, New York, NY, USA; 2010.

[63] Christensen K, Melfi R, Nordman B, Rosenblum B, Viera R. Using existing network infrastructure to estimate building occupancy and control plugged-in devices in user workspaces. International Journal of Communication Networks and Distributed Systems 2014; 12(1):4-29.

[64] Dong B, Andrews B, Lam KP, Höynck M, Zhang R, Chiou YS, Benitez D. An information technology enabled sustainability test-bed (ITEST) for occupancy detection through an environmental sensing network. Energy and Buildings 2010; 7.

[65] Foster M, Oreszczyn T. Occupant control of passive systems: the use of Venetian blinds. Building and Environment 2001; 36:149-155.

[66] Rea MS. Window Blind Occlusion: a Pilot Study. Building and Environment 1984; 19(2):133-137.

[67] Lindsay CRT, Littlefair PJ, Occupant Use of Venetian Blinds in Offices, vol. PD 233/92, Watford Building Research Establishment; 1992.

[68] Day JK, Gunderson DE. Understanding high performance buildings: The link between occupant knowledge of passive design systems, corresponding behaviors, occupant comfort and environmental satisfaction. Building and Environment 2015; 84:114-124. 
[69] Rubin AI, Collins BL, Tibbott RL. Window blinds as a potential energy saver - a case study. NSB Building Science Series 112, National Bureau of Standards, Washington, DC; 1978.

[70] O’Brien W, Kapsis K, Athienitis AK. Manually-operated window shade patterns in office buildings: A critical review. Building and Environment 2013; 60:319-338.

[71] Hunt DRG. The Use of Artificial Lighting in Relation to Daylight Levels and Occupancy. Building and Environment 1980; 14:21-33.

[72] Mahdavi A, Mohammadi A, Kabir E, Lambeva L. Occupants' operation of lighting and shading systems in office buildings, Journal of Building Performance Simulation, 2008; 1(1):57-65.

[73] Zhang Y, Barrett P. Factors influencing the occupants' window opening behaviour in a naturally ventilated office building. Building and Environment 2012; 50:125-134.

[74] Ramoser H, Schlögl T, Beleznai C, Winter M, Bischof H. Shape-based detection of humans for video surveillance. Proceedings of IEEE Int. Conf. on Image Processing 2003.

[75] Huang-Chia S. A robust occupancy detection and tracking algorithm for the automatic monitoring and commissioning of a building. Energy and Buildings 2014; 77:270-280.

[76] Johnson T, Long T. Determining the frequency of open windows in residences: a pilot study in Durham, North Carolina during varying temperature conditions. Journal of Exposure Analysis and Environmental Epidemiology 2005; 15:329-349.

[77] Brundrett GW. Ventilation: a behavioral approach. Energy research 1997; 1:289-298.

[78] Raja IA, Nicol JF, Mccartney KJ, Humphreys MA. Thermal comfort: use of controls in naturally ventilated buildings. Energy and Buildings 2001; 33:235-244.

[79] Nicol JF, MA Humphreys. Adaptive thermal comfort and sustainable thermal standards for buildings. Energy and Buildings 2002; 34(6):563-572.

[80] Wei S, Buswell R, Loveday D. Probabilistic modelling of human adaptive behaviour in non-airconditioned buildings. Proceedings of Conference: Adapting to Change: New Thinking on Comfort. Cumberland Lodge, Windsor, UK; 2010. 
[81] Veitch JA, Gifford R. Assessing Beliefs about Lighting Effects on Health, Performance, Mood, and Social Behavior. Environment and Behavior 1996; 28: 446.

[82] Peffer T, Pritoni M, Meier A, Aragon C, Perry D. How people use thermostats in homes: A review. Building and Environment 2011; 46:2529-2541.

[83] Meier H, Rehdanz K. Determinants of residential space heating expenditures in Great Britain. Energy Economics 2008; 32(5):949-959.

[84] Lutzenhiser L. A question of control: alternative patterns of room air-conditioner use. Energy and Buildings 1992; 18:193-200.

[85] Conner CC, Lucas RL. End-use load and consumer assessment program: thermostat related behavior and internal temperatures based on measured data in residences. Pacific Northwest Laboratory Report; 1990.

[86] Papakostas KT, Sotiropoulos BA, Occupational and energy behaviour patterns in Greek residences, Energy and Buildings 1997; 26:207-213.

[87] Al-Mumin A, Khattab O, Sridhar G. Occupants' behavior and activity patterns influencing the energy consumption in the Kuwaiti residences. Energy and Buildings 2003; 35:549-559.

[88] Brager GS, Paliaga G, de Dear R. Operable Windows, Personal Control, and Occupant Comfort. AHREAE Transaction Research 2004.

[89] Karjalainen S. Gender differences in thermal comfort and use of thermostats in everyday thermal environments. Building and Environment 2007; 42(4):1594-1603.

[90] Humphreys MA, Rijal HB, Nicol JF. Updating the adaptive relation between climate and comfort indoors; new insights and an extended database. Building and Environment 2013; 63:40-55.

[91] Jensen JO. Lifestyle, housing and resource consumption. Phd-thesis, Danish Building Research Institute, SBI, 2002.

[92] Haldi F, Robinson D. Modelling occupants' personal characteristics for thermal comfort prediction. International Journal of Biometeorology 2011; 55(5):681-94. 
[93] Inkarojit V. Balancing comfort: occupants' control of window blinds in private offices. PhD thesis, Univesity of California, Berkeley; 2005.

[94] Tabak V, de Vries B, Methods for the prediction of intermediate activities by office occupants, Building and Environment 2010; 45:1366-1372.

[95] Gunay HB, O'Brien W, Beausoleil-Morrison I, Goldstein R, Breslav S, Khan A. Coupling stochastic occupant models to building performance simulation using the discrete event system specification formalism. Journal of Building Performance Simulation 2014; 7:6.

[96] Stoppel CM, Leite F. Integrating probabilistic methods for describing occupant presence with building energy simulation models, Energy and Buildings 2014; 68:99-107.

[97] Liao C, Barooah P. An integrated approach to occupancy modeling and estimation in commercial buildings. ACC American Control Conference 2010; 3130-3135.

[98] Virote J, Neves-Silva R, Stochastic models for building energy prediction based on occupant behavior assessment, Energy and Buildings 2012; 53:183-193.

[99] Rijal HB, Tuohy P, Humphreys MA, Nicol JF, Samuel A, Clarke J. Using results from field surveys to predict the effect of open windows on thermal comfort and energy use in buildings. Energy and Buildings 2007; 39:823-836.

[100] Herkel S, Knapp U, Pfafferott J. Towards a model of user behaviour regarding the manual control of windows in office buildings. Building and Environment 2008; 43:588-600.

[101] Reinhart CF. Lightswitch-2002: a model for manual and automated control of electric lighting and blinds. Solar Energy 2004; 77:15-28.

[102] Andersen RV, Olesen BW, Toftum J. Modelling occupants' heating set-point preferences. Proceedings of Building Simulation, Sydney; 2011.

[103] D’Oca S, Fabi V, Andersen RK, Corgnati SP. Effect of thermostat and window opening occupant behavior models on energy use in homes. Building Simulation Journal 2014; 7:683-694. 
[104] Fabi V, Camisassi V, Causone F, Corgnati SP. Andersen RK. Light switch behaviour: occupant behaviour stochastic models in office buildings, Proceedings of $8^{\text {th }}$ Windsor Conference: Counting the Cost of Comfort in a changing world Cumberland Lodge, UK; 2014.

[105] Andersen RV, Fabi V, Toftum J, Corgnati SP, Olesen BW, Window opening behavior modelled from measurements in Danish dwellings. Building and Environment 2013; 69:101-113.

[106] Rijal HB, Tuohy P, Nicol JF, Humphreys MA, Samuel A, Clarke J. Development of an adaptive window-opening algorithm to predict the thermal comfort, energy use and overheating in buildings. Journal of Building Performance Simulation 2008; 1:17-30.

[107] Borgeson S, Brager GS. Occupant Control of Windows: Accounting for Human Behavior in Building Simulation. Center for the Built Environment, UC Berkeley. Internal Report 2008.

[108] Daum D, Morela N. Assessing the total energy impact of manual and optimized blind control in combination with different lighting schedules in a building simulation environment. Journal of Building Performance Simulation 2010; 3(1):1-16.

[109] Gunay B, O'Brien L, Beausoleil-Morrison I, Goldstein R, Breslav S, Khan A. Coupling Stochastic Occupant Models to Building Performance Simulation Using the Discrete Event System Specification (DEVS) Formalism. Journal of Building Performance Simulation 2014; 7(6):457-478.

[110] Newsham GR. Manual Control of Window Blinds and Electric Lighting: Implications for Comfort and Energy Consumption. Indoor and Built Environment 1994; 3:135.

[111] Love JA. Manual switching patterns in private offices. Lighting Research and Technology 1998; $30: 45$.

[112] Sun K, Yan D, Hong T, Guo S. Stochastic modeling of overtime occupancy and its application in building energy simulation and calibration, Building and Environment 2014;79:1-12.

[113] Jakubiec JA, Christoph F. Reinhart CF. The 'adaptive zone' - A concept for assessing discomfort glare throughout daylit spaces. Lighting Research and Technology 2012: 6 
[114] Lindelöf D, Morel N. A field investigation of the intermediate light switching by users. Energy and Buildings 2006; 38(7):790-801.

[115] Robinson D, Wilke URS, Haldi F. Multi agent simulation of occupants' presence and behavior. Proceedings of Building Simulation, Sydney; 2011.

[116] Humphreys MA, Rijal HB, Nicol JF. Updating the adaptive relation between climate and comfort indoors; new insights and an extended database. Building and Environment 05/2013;

[117] Tanimoto J, Hagishima A, Sagara H. A methodology for peak energy requirement considering actual variation of occupants' behavior schedules. Building and Environment 2008; 43:610-619.

[118] Hoes P, Hensen JLK, Loomans MCLG, de Vries G, Bourgeois D. User behavior in whole building simulation. Energy and Buildings 2009; 41:295-302.

[119] Widen J, Nilsson A, Wäckelgard E, A combined Markov-chain and bottom-up approach to modelling of domestic lighting demand, Energy and Buildings 2009; 41:1001-1012.

[120] Yun GY, Tuohy P, Steemers K. Thermal performance of a naturally ventilated building using a combined algorithm of probabilistic occupant behaviour and deterministic heat and mass balance models. Energy and Buildings 2009; 41:489-499.

[121] Pfafferott J, Herkel S. Statistical simulation of user behaviour in low-energy office buildings. Solar Energy 2007; 81:676-682.

[122] Duong B, Thi V, Hung H., Phung PQ, Svetha V. Activity recognition and abnormality detection with the switching hidden semi-Markov model, in CVPR 2005: Proceedings of the 2005 IEEE Computer Society Conference on Computer Vision and Pattern Recognition, IEEE, Washington, D. C; 2005.

[123] Dong B, Lam KP, A real-time model predictive control for building heating and cooling systems based on the occupancy behavior pattern detection and local weather forecasting, Building Simulation 2014; 7:89-106. 
[124] Degelman LO. A Model for Simulation of Daylighting and Occupancy Sensors as an Energy Control Strategy for Office Buildings, in: Proceedings of Building Simulation IBPSA Conference, Kyoto, Japan; 1999.

[125] Yamaguchi Y, Shimoda Y, Mizuno T. Development of district energy system simulation model based on detailed energy demand model. In Eighth International IBPSA Conference, Eindhoven, The Netherlands; 2003.

[126] Page J, Robinson D, Morel N, Scartezzini JL. A generalized stochastic model for the simulation of occupant presence, Energy and Buildings 2008; 40:83-98.

[127] Wang C, Yan D, Jiang Y, A novel approach for building occupancy simulation, Building Simulation 2011; 4:149-167.

[128] Kashif A, Ploix S, Dugdale J, Lea XHB. Simulating the dynamics of occupant behaviour for power management in residential buildings. Energy and Buildings 2013; 56:85-93.

[129] Langevin J, Wen J, Gurian PL. Modeling thermal comfort holistically: Bayesian estimation of thermal sensation, acceptability, and preference distributions for office building occupants. Building and Environment. 2013; 69:206-226.

[130] Langevin J, Wen J, Gurian PL. Simulating the human-building interaction: Development and validation of an agent-based model of office occupant behaviors. Building and Environment 2014: 1-19 [131] Yu Z, Haghighat F, Fung BCM, Yoshino H. A decision tree method for building energy demand modeling. Energy and Buildings 2010; 42:1637-1646.

[132] Yu Z, Fung BCM, Haghighat F, Yoshino H, Morofsky E. A systematic procedure to study the influence of occupant behavior on building energy consumption. Energy and Buildings 2011; 43:14091417.

[133] Yu Z, Haghighat F, Fung BCM, Zhou L. A novel methodology for knowledge discovery through mining associations between building operational data. Energy and Buildings 2012; 47:430-440. 
[134] D’Oca S, Hong T. A data-mining approach to discover patterns of window opening and closing behavior in offices. Building and Environment 2014; Under Press.

[135] Youngblood GM, Cook D. Data Mining for Hierarchical Model Creation. IEEE Transactions on system, man and cybernetics. 2007; 37(4).

[136] Hailemariam E, Glueck M, Attar R, Tessier A., McCrae J, Khan A. Toward a Unified Representation System of Performance-Related Data. In the 6th IBPSA Conference, Canada; 2010.

[137] EnergyPlus. Engineering Reference, Version 8.2. Copyright LBNL Press; 2014

[138] IDA ICE Indoor Climate and Energy. User Manual, Version 4.5. Copyright EQUA Simulation; 2013

[139] Hand J. The ESP-r Cookbook. University of Strathclyde, Glasgow, Scotland; 2011 http://www.esru.strath.ac.uk

[140] TRNSYS. A TRaNsient SYstem Simulation Program, Version 17.1. Copyright of the Board of Regents of the University of Wisconsin; 2013

[141] Zhu Y, Jiang Y. DeSt - A Simulation Tool in HVAC Commissioning. Proceedings of IEA ANNEX 40 Workshop. Kyoto Japan; 2003

[142] http://doe2.com/; 2014

[143] Reinhart CF. Simulation-based Daylight Performance Predictions. Book chapter in: Building Performance Simulation for Design and Operation. Taylor \& Francis; 2011

[144] http://msdn.microsoft.com/en-us/vstudio/lightswitch.aspx; 2014

[145] Turner WJN, Hong T. A technical framework to describe energy-related occupant behavior in buildings. Proceedings of BEEC Conference, Sacramento, CA; 2013

[146] Goldstein R, Tessier A, Khan A. Space layout in occupant behavior simulation. Proceedings of Building Simulation, Sydney; 2011. 
[147] Indraganti M, Rao KD. Effect of age, gender, economic group and tenure on thermal comfort: A field study in residential buildings in hot and dry climate with seasonal variations. Energy and Buildings 2010; 42(3):273-281.

[148] Parsons KC. The effects of gender, acclimation state, the opportunity to adjust clothing and physical disability on requirements for thermal comfort. Energy and Buildings 2002; 34(6):593-599.

[149] Hong T, Lin G. Occupant Behavior: Impact on Energy Use of Private Offices. Proceedings of Asim IBSPA Asia Conference; 2012.

[150] S. D’Oca, T. Hong. Occupancy schedules learning process through a data mining framework. Energy and Building 2015; 88:395-408

[151] Guerra-Santin O. Behavioural Patterns and User Profiles related to energy consumption for heating. Energy and Buildings 2011; 43:2662-2672.

[152] Dong B, Lam KP, Building energy and comfort management through occupant behavior pattern detection based on a large-scale environmental sensor network. Journal of Building Performance Simulation 2011; 4(4):359-369.

[153] Fanger PO. Thermal comfort. Analysis and applications in environmental engineering. Danish Technical Press Copenhagen, Denmark, 1970.

[154] de Dear R, Brager G. Developing an Adaptive Model of Thermal Comfort Preference. ASHRAE Transactions 1998; 104(1):27-49.

[155] Hawkes D, Owers J. User response in environmental control. The Architecture of Energy, Eds. London: Construction Press/Longmans. 1981:45-63.

[156] Milliken ME Understanding human behavior: a guide for health care providers. The Free Press; 1965. 


\section{Figures and tables with captions}

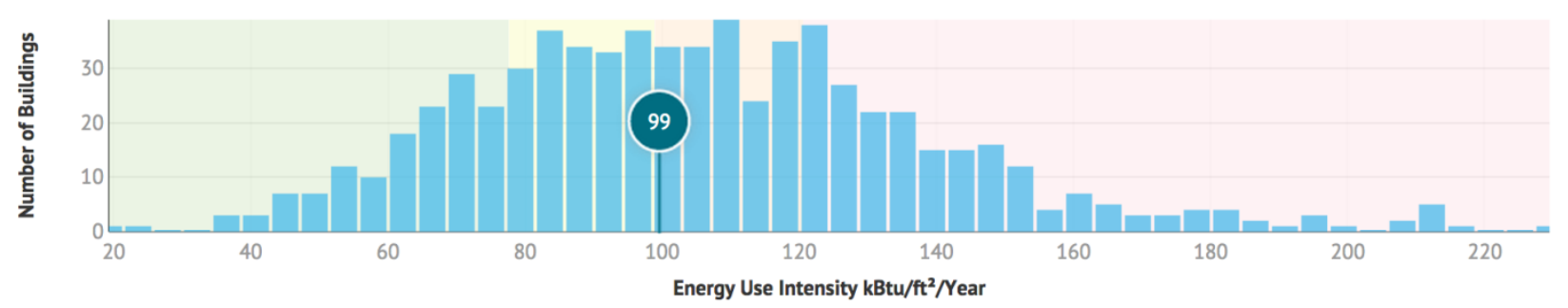

Figure 1: Distribution of delivered energy intensities for commercial buildings in Baltimore, USA [4].

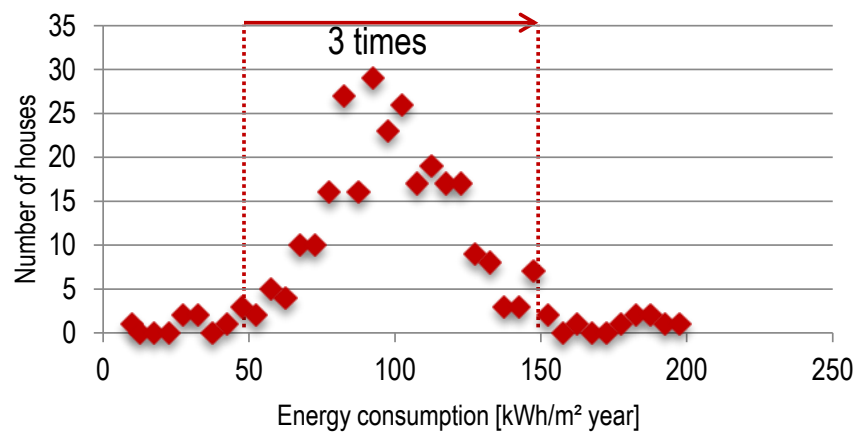

Figure 2: Energy consumption of 35 apartments of the same block of building in Copenhagen, EU [5].

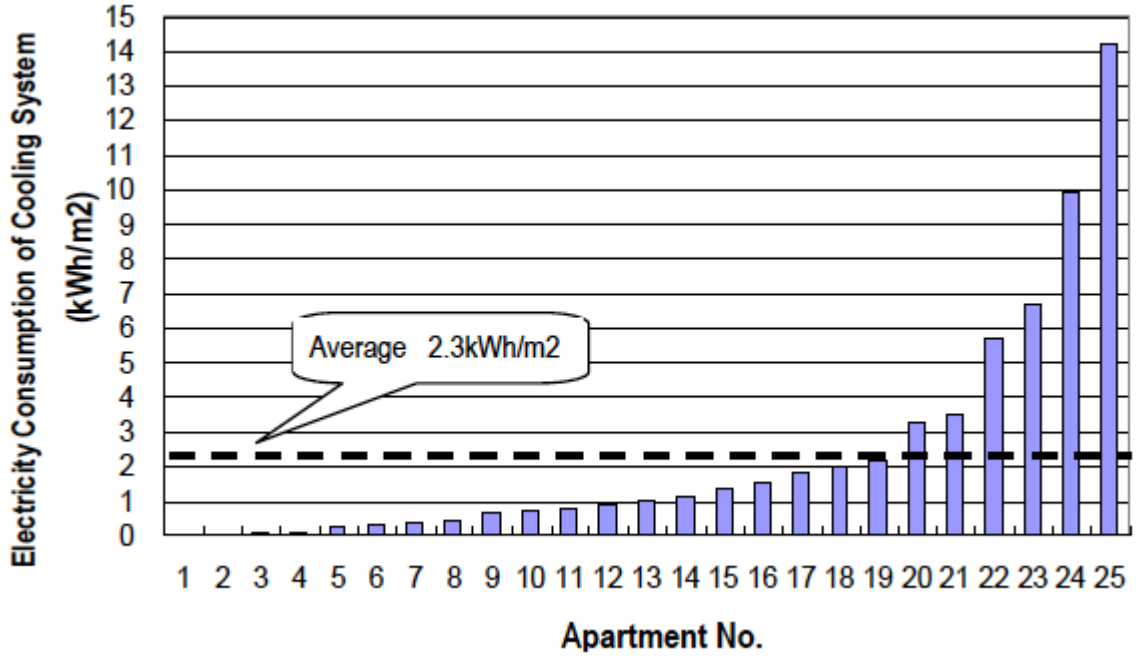

Figure 3: Residential building summer air-conditioning electricity consumption, Beijing, China. [6]. 


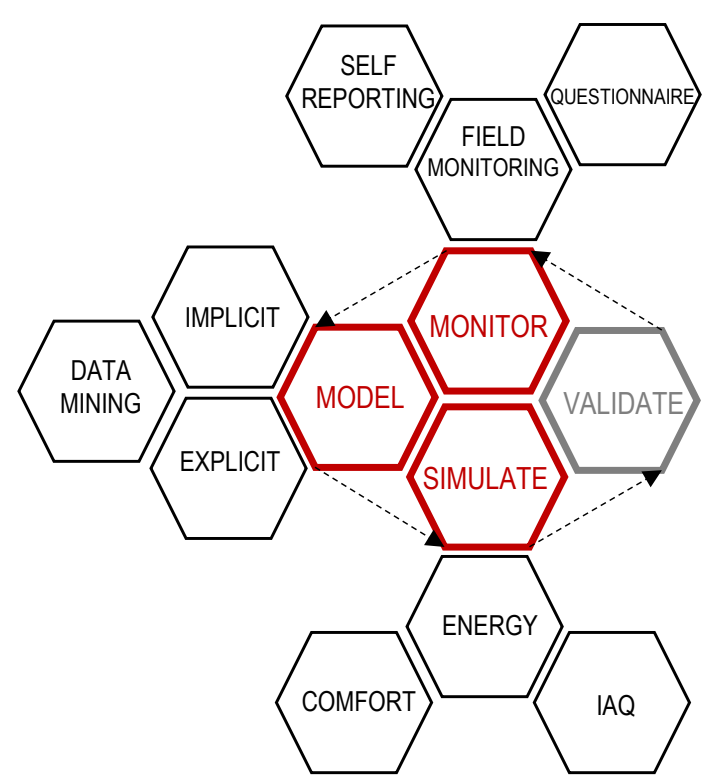

Figure 4: Graphical representation of the methodological approach on occupant behavior modeling

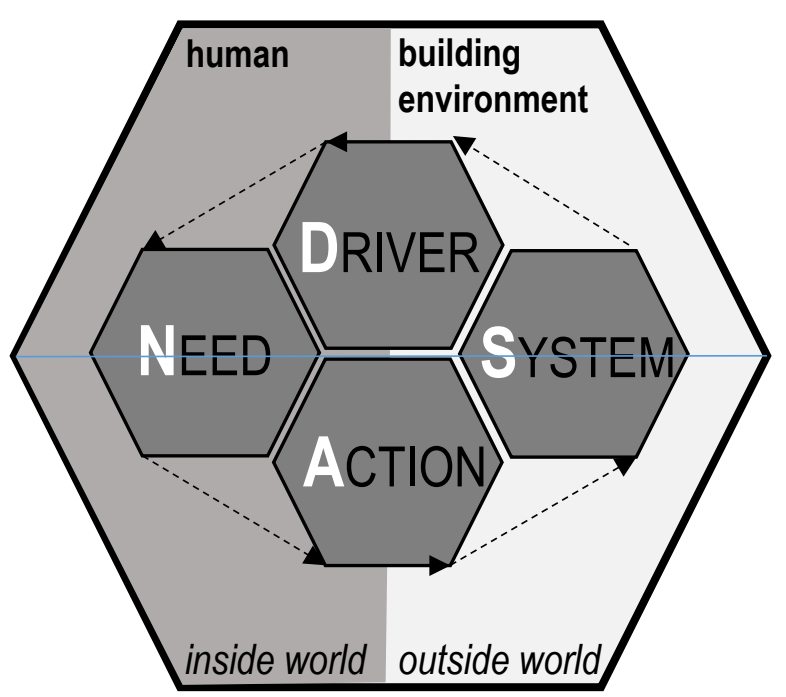

Figure 5: Four key components of the human-building environment interaction framework 


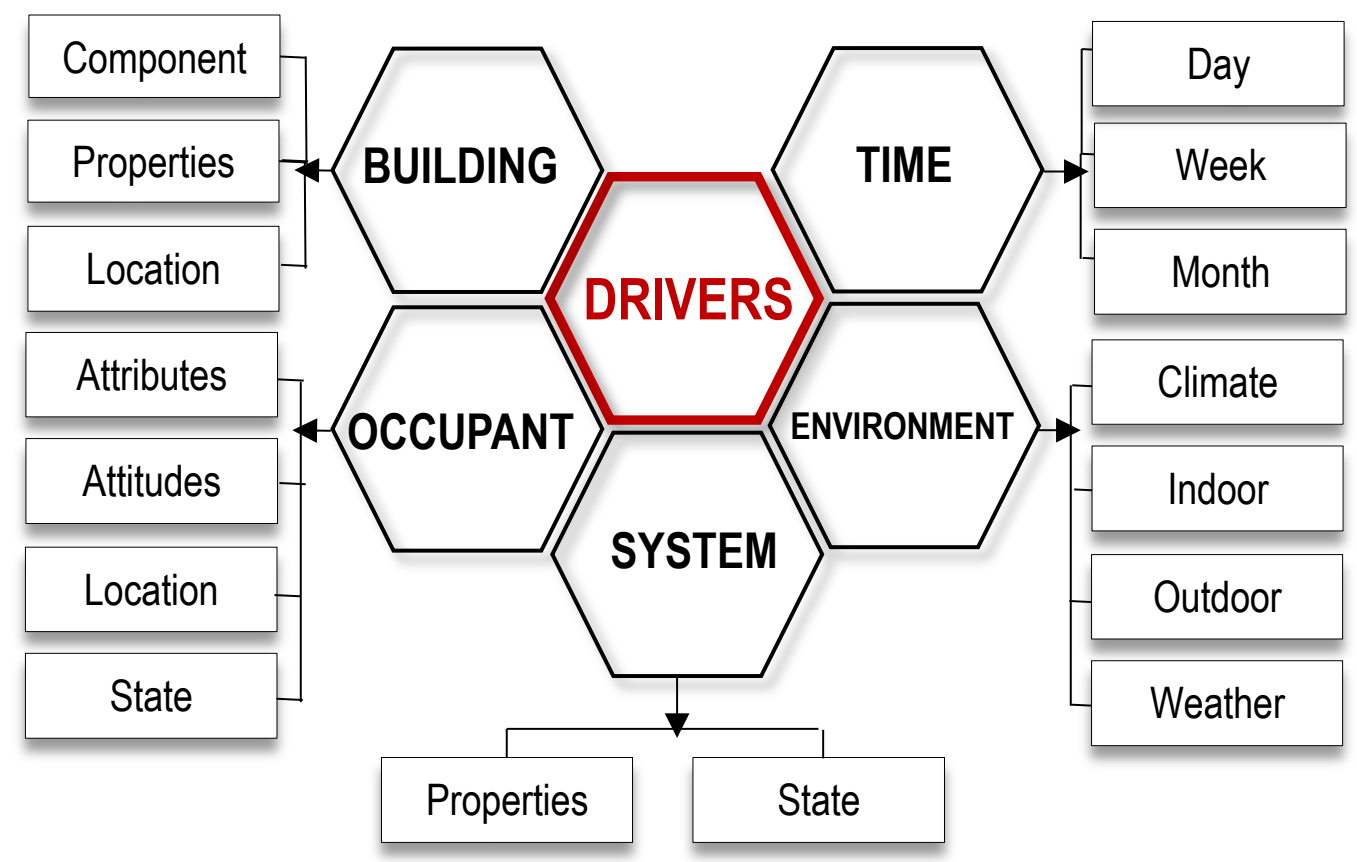

Figure 6: Drivers behind energy-related occupant behavior

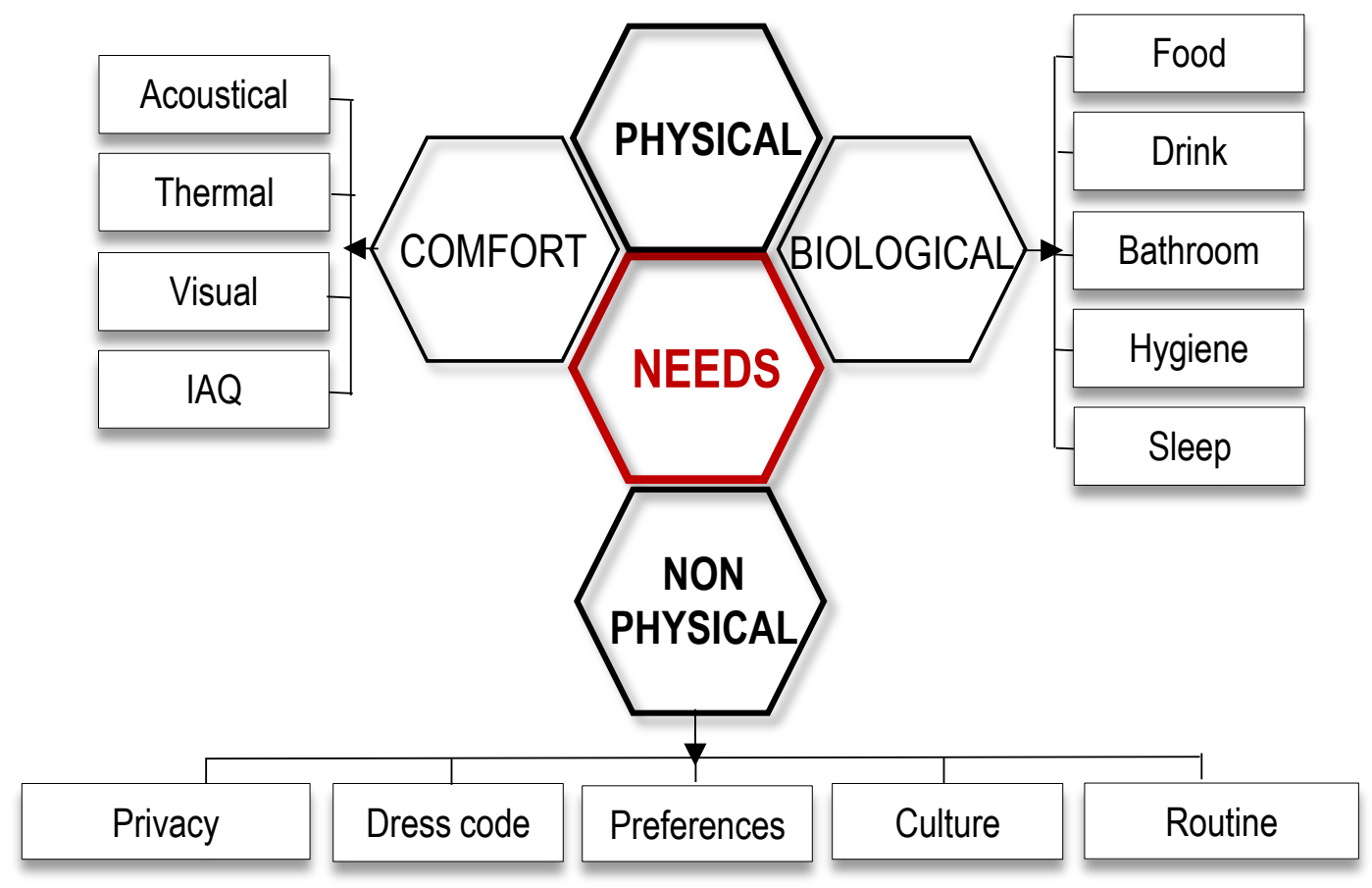

Figure 7: Needs of building occupants that may result in an action that changes the building energy use 


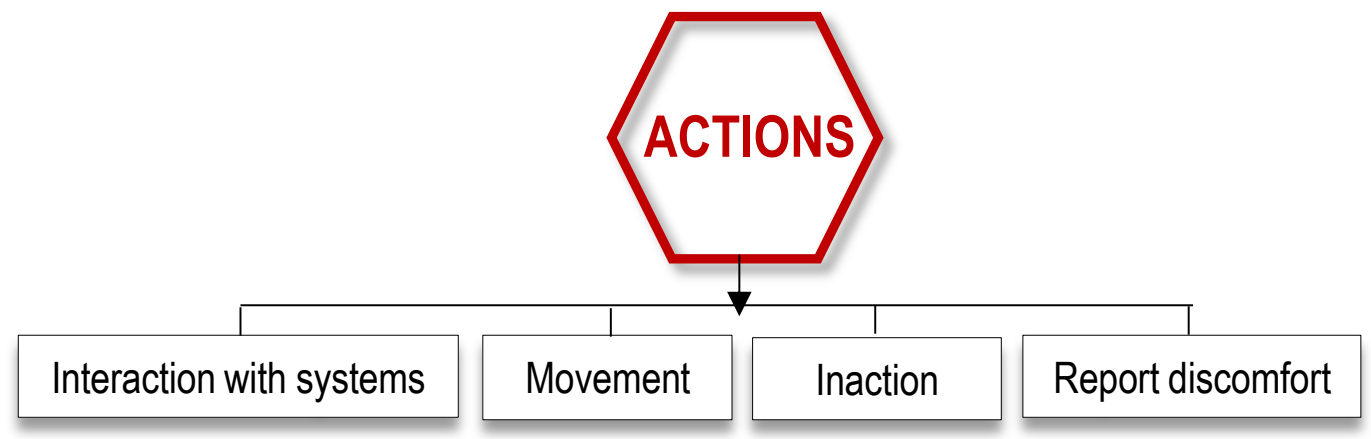

Figure 8: Actions undertaken by building occupants when their needs are not met

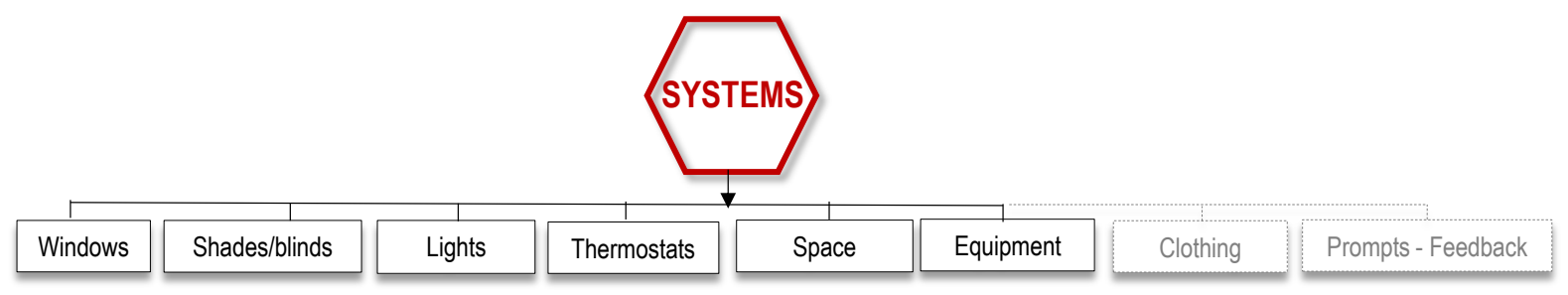

Figure 9: Building systems with which an occupant may interact causing a change in building energy use

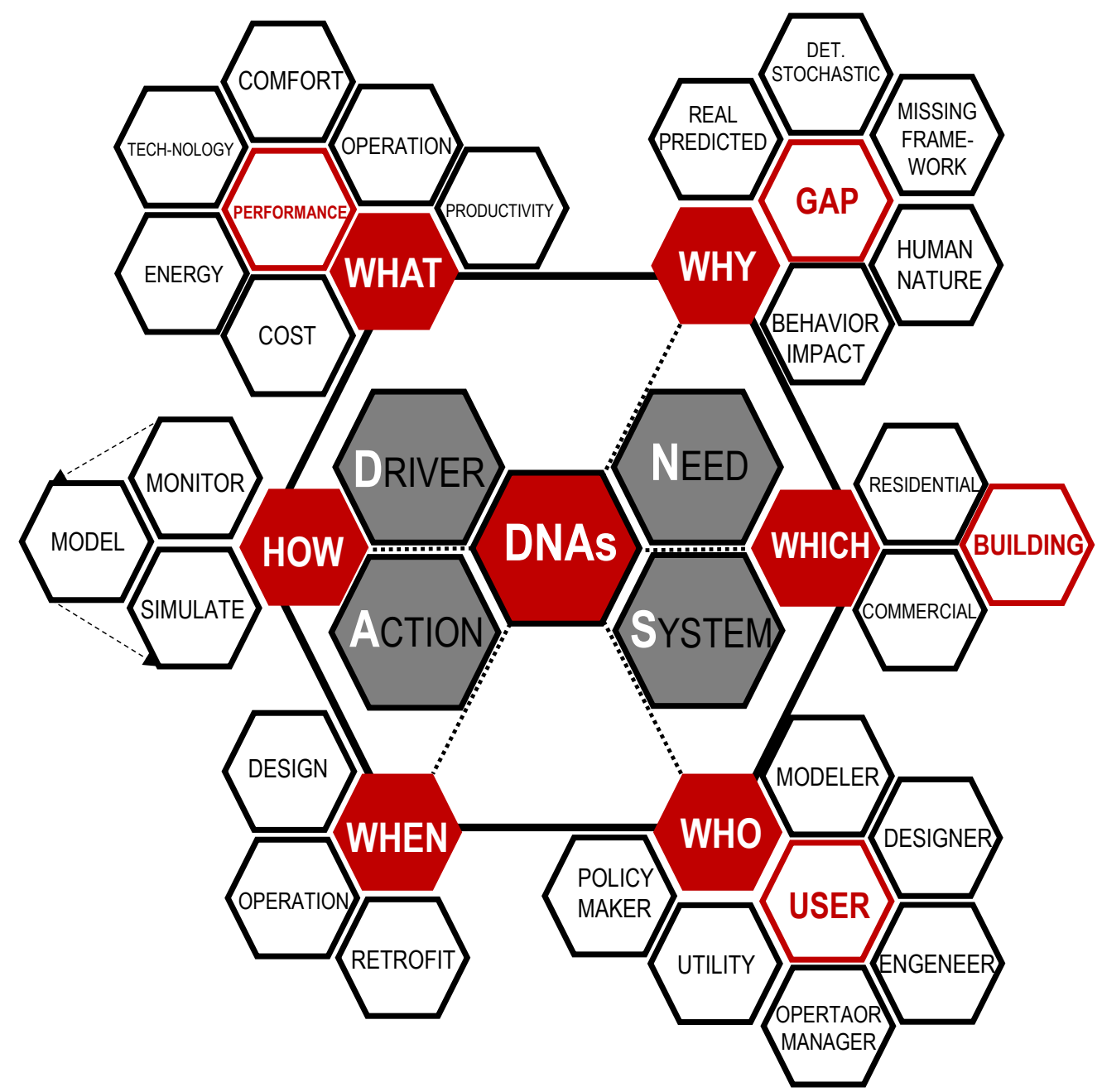

Figure 10: A graphical representation of the DNAs framework applications 
Table 1. Theoretical framework of human behavior

\begin{tabular}{llll}
\hline Acronym & Name & Author & Date \\
\hline PCT & Perceptual Control Theory & Powers [11] & 1953 \\
HOS & Human Operator Simulator & Wherry [12] & 1976 \\
CCT & Cognitive Complex Theory & Card et al. [13] & 1983 \\
EPIC & Executive Process Interactive Control & Kieras and Meyer [14] & 1995 \\
SOAR & State, Operator and Result & Lehman et al. [15] & 1996 \\
ACT & Adaptive Control of Thought & Anderson and Liebere & 1998 \\
COGNET & Cognition as a Network of Task & Zachary et al. [17] & 1998 \\
APEX & Architecture for Procedure Execution & Freed [18] & 1998 \\
BRAHMS & Business Redesign Agent-Based Holistic Modelling System & Sierhuis et al. [19] & 2007 \\
\hline
\end{tabular}

Table 2. Typical building components and characteristics included in published simulation models of occupant behavior

building type (office, residential)

spaces layout, geometry, location

building envelope thermo-physical characteristics

façade orientation and height

window geometry and height

type of window device (manual/motorized/automated)

type of dwelling (detached house, house, flat)

type of office (open space, cubicle, private vs. shared office)

type of ventilation system (natural, mechanical, mixed-mode, night ventilation)

type of HVAC/AC system

type of lighting control (manual/automatic)

type of shade device (manual/motorized/automated)

internal loads, occupancy schedules

type of indoor temperature control 
Table 3. Typical metrics and simulation outputs included in published simulation models of occupant behavior

\begin{tabular}{|c|c|c|c|c|c|c|}
\hline techniques & windows & shade/blinds & lighting system & thermostat & space occupancy & plug loads \\
\hline metrics & $\begin{array}{l}\text { air change rate } \\
(\mathrm{n} / \mathrm{h}) \\
\text { ventilation losses } \\
(\mathrm{kwh} / \mathrm{m} 2) \text {, } \\
\text { thermal comfort, } \\
\text { indoor air quality }\end{array}$ & $\begin{array}{l}\text { mean shade } \\
\text { occlusion (MSO) } \\
\text { shade movement } \\
\text { rate (SMR) } \\
\text { visual/thermal } \\
\text { comfort, } \\
\text { glare discomfort } \\
\text { index }\end{array}$ & $\begin{array}{l}\text { daylight } \\
\text { illuminance level } \\
\text { (lux) } \\
\text { light switch } \\
\text { frequency, } \\
\text { visual comfort }\end{array}$ & $\begin{array}{l}\text { primary energy } \\
\text { consumption for } \\
\text { space heating } \\
\left(\mathrm{kwh} / \mathrm{m}^{2}\right) \\
\text { internal gains } \\
\text { thermal comfort }\end{array}$ & $\begin{array}{l}\text { occupancy rates, } \\
\text { nominal } \\
\text { occupancy } \\
\text { profiles, } \\
\text { vacancy activity, } \\
\text { transition } \\
\text { probability, } \\
\text { presence/absence } \\
\text { probability and } \\
\text { distribution, } \\
\text { frequent pattern } \\
\text { detection }\end{array}$ & $\begin{array}{l}\text { occupancy } \\
\text { patterns, } \\
\text { operational } \\
\text { schedules }\end{array}$ \\
\hline
\end{tabular}


Appendix A

\begin{tabular}{|c|c|c|c|c|c|c|c|}
\hline \multicolumn{2}{|c|}{ Techniques } & \multirow{2}{*}{\begin{tabular}{|l} 
WINDOWS \\
Magnetic switches \\
{$[5,2-25,105,134]$}
\end{tabular}} & \multirow{2}{*}{\begin{tabular}{|l} 
SHADE/BLINDS \\
$\begin{array}{l}\text { Electromechanical sensors } \\
{[29,30,93]}\end{array}$
\end{tabular}} & \multirow{2}{*}{\begin{tabular}{|l|} 
LIGHTING SYSTEM \\
$\begin{array}{l}\text { Electromechanical } \\
\text { sensors }[31,119,122]\end{array}$ \\
\end{tabular}} & \multirow{2}{*}{\begin{tabular}{|l|}
$\begin{array}{l}\text { THERMOSTAT SET } \\
\text { POINTS }\end{array}$ \\
$\begin{array}{l}\text { TRV / cooler } \\
\text { temperature set point } \\
{[33-36,120]}\end{array}$ \\
\end{tabular}} & \multirow{2}{*}{\begin{tabular}{|l} 
SPACE OCCUPANCY \\
Presence detectors \\
{$[42,43,94-98,109,112$} \\
$115,123,124,126,136$ \\
$149,150]$
\end{tabular}} & \multirow{2}{*}{\begin{tabular}{|l|} 
EQUIPMENT \\
$\begin{array}{l}\text { Smart plugs, electrical } \\
\text { current measurement, } \\
\text { wireless electric outlet } \\
\text { meters [45-52] }\end{array}$ \\
\end{tabular}} \\
\hline & $\begin{array}{l}\text { SENSORING the } \\
\text { CONTROL SYSTEM } \\
\text { directly }\end{array}$ & & & & & & \\
\hline & \begin{tabular}{|l} 
SENSORING the \\
CONTROL SYSTEM \\
indirectly
\end{tabular} & $\begin{array}{l}\text { CO2 concentration level } \\
\text { Vaisala GMW22 sensor } \\
\text { [26], WMA-3 monitor [53]. } \\
\text { Tracer gas techniques } \\
\text { [55-58] }\end{array}$ & & $\begin{array}{l}\text { Electrical recording of } \\
\text { the illuminance level } \\
\text { luxometer [60], } \\
\text { photometer [32] }\end{array}$ & \begin{tabular}{|l} 
Gas energy use \\
heated floor area [61], \\
heat flux meters, air and \\
water flow meters, power \\
meters [42]
\end{tabular} & $\begin{array}{l}\text { CO2 concentration [54], } \\
\text { light switch sensors [59], } \\
\text { computer switch }[62,63] \\
\text { computer IP address [64], } \\
\text { sensor network [152] }\end{array}$ & \\
\hline \multirow{3}{*}{ 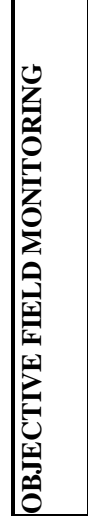 } & $\begin{array}{l}\text { SENSORING physical } \\
\text { and non-physical } \\
\text { variables }\end{array}$ & \begin{tabular}{|l} 
Indoor and outdoor \\
parameters \\
{$[21,25,26,28,53,55,99$} \\
$100,105-107]$
\end{tabular} & $\begin{array}{l}\text { Indoor and outdoor } \\
\text { parameters } \\
{[30,32,65-67,72,73,78} \\
93,101,110]\end{array}$ & \begin{tabular}{|l} 
Indoor and outdoor \\
parameters \\
{$[41,101,104,108,110$,} \\
$111,113,114,143]$
\end{tabular} & $\begin{array}{l}\text { Indoor and outdoor } \\
\text { parameters } \\
{[35,83-87,102,151]}\end{array}$ & $\begin{array}{l}\text { Indoor and outdoor } \\
\text { parameters } \\
{[123]}\end{array}$ & \\
\hline & \begin{tabular}{|l} 
PHOTOGRAPHIC \\
ANALYSIS
\end{tabular} & $\begin{array}{l}\text { TIME LAPSE } \\
\text { PHOTOGRAPHY of the } \\
\text { exterior of the building } \\
\text { façade }[23,28,73,93]\end{array}$ & $\begin{array}{l}\text { TIME LAPSE } \\
\text { PHOTOGRAPHY of the } \\
\text { exterior of the building } \\
\text { façade }[29,32,65-70] \text {. }\end{array}$ & $\begin{array}{l}\text { TIME LAPSE } \\
\text { PHOTOGRAPHY of } \\
\text { the interior of the } \\
\text { building façade }[71,72]\end{array}$ & & \begin{tabular}{|l} 
Camera-based methods \\
{$[74,75]$}
\end{tabular} & \\
\hline & $\begin{array}{l}\text { INTERNAL VISUAL } \\
\text { SURVEY (personal } \\
\text { observation and } \\
\text { record ) }\end{array}$ & Building walkthroughs $[76]$ & \begin{tabular}{|l} 
Building walkthroughs \\
{$[93]$}
\end{tabular} & $\begin{array}{l}\text { Building walkthroughs } \\
{[31]}\end{array}$ & & & \\
\hline \multicolumn{2}{|c|}{ Techniques } & WINDOWS & SHADE/BLINDS & LIGHTING SYSTEM & $\begin{array}{l}\text { THERMOSTAT SET } \\
\text { POINTS }\end{array}$ & SPACE OCCUPANCY & EQUIPMENT \\
\hline \multirow[b]{2}{*}{ 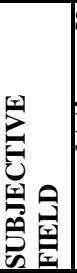 } & SELF REPORTING & \begin{tabular}{|l} 
Questionnaires \\
{$[24,26]$}
\end{tabular} & & & \begin{tabular}{|l} 
Questionnaires \\
{$[102,151]$}
\end{tabular} & & \\
\hline & $\begin{array}{l}\text { INTERVIEW } \\
\text { TECHNIQUES }\end{array}$ & \begin{tabular}{|l} 
Questionnaires $[23,55,73$, \\
$77,78,80,88]$ \\
Mail survey $[99]$ \\
Web based survey $[88,107]$
\end{tabular} & \begin{tabular}{|l} 
Questionnaires \\
{$[29,30,50,65,73,78]$}
\end{tabular} & \begin{tabular}{|l} 
Questionnaires \\
{$[31,81]$}
\end{tabular} & \begin{tabular}{|l} 
Questionnaires \\
{$[82-85,89]$}
\end{tabular} & & \begin{tabular}{|l} 
Questionnaires \\
{$[52,86,87]$}
\end{tabular} \\
\hline
\end{tabular}


Appendix B

\begin{tabular}{|c|c|c|c|c|c|c|}
\hline Techniques & WINDOWS & SHADE/BLINDS & LIGHTING SYSTEM & THERMOSTAT SET POINTS & SPACE OCCUPANCY & EQUIPMENT \\
\hline \begin{tabular}{|l|} 
IMPLICIT \\
MODELS \\
Stochastic \\
models
\end{tabular} & $\begin{array}{l}\text { Single variable linear }[76] \\
\text { and logistic regression } \\
{[23,73]} \\
\text { Multi variable logistic } \\
\text { regression } \\
{[5,36,53,100,103,105-} \\
107,115]\end{array}$ & \begin{tabular}{|l}
$\mid$ Lightswitch algorithm \\
{$[41,101,113,143]$} \\
Single variable logistic \\
regression [22, 28, 29] \\
Multivariate logistic \\
regression \\
{$[93,95,108,109]$}
\end{tabular} & \begin{tabular}{|l|} 
Lightswitch algorithm \\
{$[41,101,104,110,113,143]$} \\
Linear regression analysis $[91]$ \\
Probability equation \\
{$[49,71,72,111]$} \\
SHOCC Sub Hoursly \\
Occupancy based control model \\
{$[48]$} \\
Bayesian estimations $[114]$
\end{tabular} & \begin{tabular}{|l|} 
Statical analysis $[33,35,151]$ \\
Linear regression analysis [37] \\
Multivariate Logistic Regression \\
{$[36,102,103]$}
\end{tabular} & \begin{tabular}{|l|} 
Statistical analysis \\
{$[40,59,112,149]$} \\
Logistic regression models \\
{$[94-98]$} \\
SHOCC Sub Hourly \\
Occupancy based control \\
model $[118]$
\end{tabular} & $\begin{array}{l}\text { Logistic regression models } \\
{[46-48,52}\end{array}$ \\
\hline \begin{tabular}{|l} 
EXPLICIT \\
MODELS \\
Monte \\
Carlo \\
Simulation
\end{tabular} & \begin{tabular}{|l|} 
Discrete Marcov Chain \\
{$[21,25,50,80,100,121]$}
\end{tabular} & $\begin{array}{l}\text { Markov Chain }[22,32, \\
50]\end{array}$ & Markov Chain $[115,119]$ & Markov Chain $[50,79,117]$ & \begin{tabular}{|l|} 
Semi Markov model [122] \\
Hidden Markov model [123] \\
Agent based model [124-130]
\end{tabular} & $\begin{array}{l}\text { Markov chain, semi-Markov } \\
\text { process [49-51] }\end{array}$ \\
\hline Data mining & $\begin{array}{l}\text { Cluster Analysis, } \\
\text { Association Rules Mining } \\
{[134]}\end{array}$ & & & & \begin{tabular}{|l|} 
Cluster analysis, association \\
rules [131-134] \\
Hierarchical models [135] \\
Decision trees [136]
\end{tabular} & \begin{tabular}{|l} 
Cluster Analysis, Association \\
Rules Mining [131-133, 135]
\end{tabular} \\
\hline
\end{tabular}

